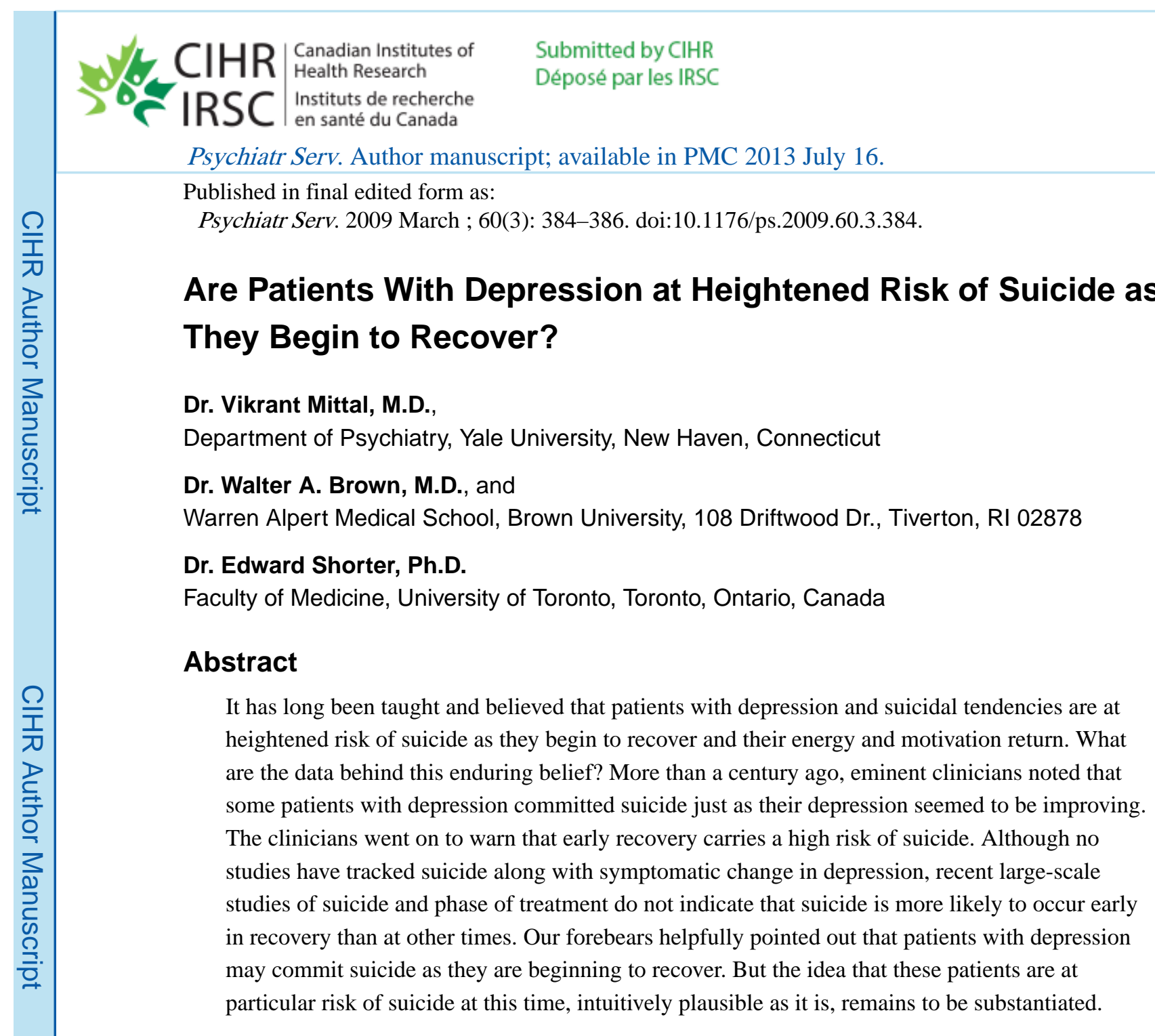

The idea that patients with depression and suicidal tendencies are at heightened risk of suicide as they begin to recover from depression is widely taught and believed. It is enshrined, among other places, in the American Psychiatric Association's Practice Guideline for the Assessment and Treatment of Patients With Suicidal Behaviors (1). According to the guideline, "clinical observations suggest that there may be an early increase in suicide risk as depressive symptoms begin to lift but before they are fully resolved" (1). The increased energy and motivation that come with depression relief, so the thinking goes, increase the likelihood that patients will act on their suicidal impulses. This idea has been around for a long time; it can be traced to the early writings of Benjamin Rush, Emil Kraepelin, and Eugen Bleuler, among others. But are there any data to support it?

\title{
History
}

Benjamin Rush, in his 1812 textbook Medical Inquiries and Observations Upon the Diseases of the Mind (2), cautioned that "we should be careful between a return of reason and a

Correspondence to: Walter A. Brown.

Disclosures

The authors report no competing interests. 
certain cunning, which enables mad people to talk and behave correctly for a short time, and thereby to deceive their attendants, so as to obtain a premature discharge from their place of confinement." In the same book he noted that "three instances of suicide have occurred in patients soon after they left the Pennsylvania Hospital, and while they were receiving the congratulations of their friends upon their recovery."

In 1896, Emil Kraepelin, professor of psychiatry at the University of Heidelberg, urged careful supervision of inpatients during the transition to complete remission. "At this time," Kraepelin wrote, "a certain activation has occurred alongside the depression of mood, the patients are most dangerous to themselves, although their condition appears much improved compared to the depths of the depression" (3). He noted that "Often, I saw precisely at that moment suicide attempts that previously were not undertaken because of the lack of volition, despite great tedium of life. Just recently a patient with a quite minor depression hanged himself a few days before his discharge, having already appeared conspicuously cheerful" (3).

In 1915, J. Barfield Adams (4) reiterated these observations. "It is a matter of common knowledge," he wrote, "that it is in the early stages of melancholia that suicide is most likely to occur."

And in 1916, Eugen Bleuler, professor of psychiatry in Zurich, weighed in on the matter: "Especially dangerous," he wrote, "are the periods of recovery, when the suicidal drive is still at least occasionally present but the patient's energy is no longer so extremely crippled, the energy of the supervisory staff however having begun to slacken" (5).

These statements by eminent clinicians make sense on intuitive clinical grounds, but the fact that these clinicians and some subsequent ones have known of depressed patients who committed suicide as they were recovering does not support the widely believed notion that patients are at increased risk of suicide at this time. It merely indicates that suicide can occur just as patients are getting better. Whether patients with depression are in fact at particular risk of suicide at this time is of more than theoretical interest. If this widely believed notion is correct, patients should be more carefully and frequently observed at this phase of their illness than at others.

\section{The data}

We searched databases available through Ovid—Medline and PsycIN-FO—from their start dates (1950 and 1806, respectively) to the present for the terms "depression and suicide," "suicide during recovery from depression," and "suicidality during depression." We also examined the bibliographies of eight recent books, including standard psychiatric texts and books focused on suicide, as well as the reference lists of the articles cited in this Open Forum for references covering these topics. We found no studies that provided data on suicide or suicidality as patients are recovering from depression. Although no studies directly evaluated suicide in relation to stage of depressive illness or its symptoms, several studies provide data bearing indirectly on this matter. 
Copas and his colleagues (6), seeking to identify the danger periods for suicide during treatment of depression, conducted a retrospective study of 29 patients who committed suicide while they were in treatment. The authors looked at suicide risk in relation to length of treatment. The results of their complex statistical analysis suggested a slight trend for increased suicide risk both at the beginning and near the end of a treatment period for depression.

Prompted by recent concerns that antidepressants precipitate suicide, a number of investigators have retrospectively examined suicidal behavior in relation to antidepressant treatment. Jick and colleagues (7) conducted a case-control study (555 cases) that focused on nonfatal suicidal behavior and suicide by patients treated with various antidepressants. They found that both suicidal behavior and suicide rate increased during the first month of treatment, particularly during the first nine days.

On the other hand, Simon and colleagues (8) used computerized health plan records to identify 65,103 patients who had received antidepressant prescriptions between 1992 and 2003. The risk of suicide was not higher in the month after starting an antidepressant than in subsequent months. Risk of suicide attempts peaked in the month before starting antidepressant treatment and declined thereafter. In a subsequent study of more than 100,000 patients treated with antidepressants or psychotherapy, Simon and Savarino (9) found a similar pattern of suicide attempts. For both treatment modalities the frequency of attempts peaked in the month before treatment began, was next highest in the first month of treatment, and declined thereafter. Similarly, in a study of suicide attempts among 226,866 veterans with depression, Gibbons and colleagues (10) found that suicide attempt rates were higher before the start of treatment than after.

Schweizer and his associates (11) directly challenged what they called the "clinical pearl"handed down to "generations of physicians-in-training"- that early stages of recovery from depression come with "an increased suicide vulnerability since a patient may finally be mobilizing enough energy to act on suicidal impulses he or she has long but passively harbored." They described two patients who committed suicide soon after apparent recovery. But in fact both patients experienced brief hypomanic episodes early in the course of treatment for depression, switched rapidly into depression, and committed suicide soon after the switch. The authors suggested that cycling of mood, with its inherent risk of suicide, is a more plausible explanation than a mobilization of enough energy to commit the act for suicides that occur in the early stages of "recovery" from depression. Accordingly, they cautioned clinicians to be alert to a history of hypomania and a diagnosis of bipolar disorder II.

\section{Discussion}

Beyond the clinical observation that some patients with depression who commit suicide do so as they begin to recover-and the impression of some influential clinicians that the time of early recovery is one of heightened risk of suicide - there are no data that track suicide in relation to symptoms. If the phase of antidepressant treatment when improvement is likely to begin is considered a proxy for improvement, the studies that track suicide in relation to the 
initiation of antidepressant treatment do not collectively support the notion of heightened risk of suicide as recovery begins.

The results of Jick and colleagues' study (7), which found a heightened suicide risk during the first nine days of antidepressant treatment and to a lesser extent during the first month of treatment, could be interpreted as providing support for the theory of increased risk during early recovery. Yet these authors maintain that "the most likely explanation for this finding is that antidepressant treatment may not be immediately effective, so there is a higher risk of suicidal behavior in patients newly diagnosed and treated than in those who have been treated for a longer time" (7). The other studies that tracked suicidal behavior in temporal relation to treatment suggest that the risk of such behavior is higher before than after treatment. Thus the data that bear, albeit indirectly, on suicide risk in relation to phase of depression provide no consistent support for the belief that suicide risk increases as patients begin to recover; if anything, they refute it. Schweizer and colleagues (11) wrote, "As superficially appealing as the long-held mobilization-of-energy hypothesis is, it has little in the way of evidence to substantiate it." We agree.

One can only speculate about what lay behind the conviction of Kraepelin (3), Bleuler (5), and Rush (2), that the early recovery period holds particular danger. One possibility is that suicides that occur when patients seem to be improving are unexpected-even paradoxicaland therefore they are particularly memorable. When instances of an event come readily to mind, they are perceived as being more frequent than in fact they are (12). For this reason and perhaps because of its intuitive appeal, the notion of heightened risk early in recovery now has the quality of received wisdom. Of the half-dozen suicide experts we spoke to, all said they had been taught the theory and believed it to be true. Although a few thought that there must be some studies that back the idea, none could actually point to any data in support of it. "It's something clinicians just know," one said.

Although the data that track suicide in relation to the initiation of antidepressant treatment do not support the widely believed notion that patients are at heightened risk of suicide as they begin to recover, the early phases of treatment are far from a reliable proxy for improvement. In the absence of data bearing directly on the relationship between suicide and early recovery, the idea that early recovery comes with particular risk of suicide is a plausible clinical hunch that remains unproven. Without some substantiating data, this hunch does not warrant its long-held status as established truth.

Our wise clinical forebears correctly pointed out that patients with depression commit suicide not only in the depths of despair but also as they begin to recover. Clinicians need to be vigilant for suicidal behavior throughout the course of a patient's depressive illness.

\section{References}

1. Practice guideline for the assessment and treatment of patients with suicidal behaviors. American Journal of Psychiatry. 2003; 160(v suppl):1-60.

2. Rush, B. Medical Inquiries and Observations Upon the Diseases of the Mind. Philadelphia: Kimber and Richardson; 1812.

Psychiatr Serv. Author manuscript; available in PMC 2013 July 16. 
3. Kraepelin, E. Psychiatry: A Textbook for Students and Physicians. 5. Leipzig: Barth; 1896. [in German]

4. Adams JB. Suicide from a general practitioner's point of view. Practitioner. 1915; 44:470-478.

5. Bleuler, E. A Textbook of Psychiatry [in German]. Berlin: Springer; 1916.

6. Copas JB, Freeman-Browne DL, Robin AA. Dangerous periods for suicide in patients under treatment. Psychological Medicine. 1971; 1:400-404. [PubMed: 5158636]

7. Jick H, James AK, Jick SS. Antidepressants and the risk of suicidal behaviors. JAMA. 2004; 292:338-343. [PubMed: 15265848]

8. Simon GE, Savarino J, Operskalski B, et al. Suicide risk during antidepressant treatment. American Journal of Psychiatry. 2006; 163:41-47. [PubMed: 16390887]

9. Simon GE, Savarino J. Suicide attempts among patients starting depression treatment with medications or psychotherapy. American Journal of Psychiatry. 2007; 164:1029-1034. [PubMed: 17606654]

10. Gibbons RD, Brown $\mathrm{CH}$, Hur K, et al. Relationship between antidepressants and suicide attempts: an analysis of the Veterans Health Administration data sets. American Journal of Psychiatry. 2007; 164:1044-1049. [PubMed: 17606656]

11. Schweizer E, Dever A, Clary C. Suicide upon recovery from depression: a clinical note. Journal of Nervous and Mental Disease. 1988; 176:633-636. [PubMed: 3183647]

12. Tversky, A., Kahneman, D. Availability: a heuristic for judging frequency and probability. In: Kahneman, D.Slovic, P., Tversky, A., editors. Judgement Under Uncertainty: Heuristics and Biases. Cambridge, United Kingdom: Cambridge University Press; 1982. 